\title{
STUDY OF MIS MULTICRYSRALINE SILICON THIN-FILM SOLAR CELL
}

\author{
A. A. El-Amin ${ }^{1}$, M. K. Hassan ${ }^{2}$ \\ ${ }^{1}$ Physics Department, faculty of Science, Aswan \\ ${ }^{2}$ Engineering Materials \& Mech. Design Department, High Institute of Energy, \\ South Valley University, 81528 Aswan, Egypt \\ E-mail:aaelamin2000@yahoo.com
}

(Received April 10, 2008 Accepted October 25, 2008)

\begin{abstract}
State-of-the-art of multicrystalline Silicon ( $m c$-Si) material with minority carrier diffusion lengths exceeding the wafer thickness is commercially available today. It is expected that the diffusion length to wafer thickness ratio will be increasing further due to improved material quality and due to the trend towards thinner wafers to reduce material costs. As a result, the open circuit voltage, $V_{\text {oc }}$ decreases with increasing temperature according the ratio $\Delta V_{o c} \Delta T=-0.00337 \mathrm{mVK}^{-1}$. The output power decrease with increasing temperature mainly because of a decrease in the photovoltaic and fill factor of the current voltage characteristic. This happens in samples which have $\Delta P / \Delta T=-0.00048 W^{-1}, \Delta F F / \Delta T=$ $-0.002 \% K^{1}$, and $\Delta R / \Delta T=-0.021 \Omega K^{1}$. In order to fully exploit the material quality, a solar cell process that includes excellent rear surface passivity is needed. In this paper solar cell results from thin mc-Si solar cells with silicon nitride front and rear surface passivity are presented. Furthermore, the most important loss mechanisms with respect to thin mc-Si cells namely : (i) optical losses, (ii) losses due to rear surface recombination and (iii) losses due to the series resistance caused by local rear contact schemes with dielectric passivity are discussed. The light trapping effect of this structure is also confirmed reflection at the weakly absorbed wavelength.
\end{abstract}

\section{INTORDUCTION}

The Metal-Insulator-Semiconductor $(M I S)$ structure is currently receiving attention in solar cell research [1-8]. It has several advantages over p-n junctions; first, MIS structure considerably simpler to fabricate, thus is reducing the overall cell cost drastically. Secondly, metal deposition methods are consistent with high yield, fast, through out processing, and also involve low substrate temperature.

In practice an intimate contact metal-insulator solar cell exhibits a serious deficiency in the form of very poor photovoltage response. It is possible to overcome the disadvantage of metal-semiconductor solar cell by allowing a very thin insulating layer to separate the metal and semiconductor. The prediction and control of the electrical properties of the ultra thin metallic films in MIS solar cells are proved to be very important since the sheet resistance loss in these films contributes to the fill factor loss of the solar cell. 
Typical industrial rear surface schemes for $m c-S i$ are full area aluminum $(A l)$ metallization or a full area $A l$ back surface field $(A l-B S F)$ that have no or only moderate passivity quality. Recently, mc-Si solar cells with evaporated thin layer of $\mathrm{Al}$ using the vacuum evaporator were presented $[9,10,11]$.

\section{EXPERIMENTAL WORK}

MIS contacted diffused $p$ - $n$ junction silicon solar cells $\left(2 \times 2 \mathrm{~cm}^{2}\right.$ device area) were fabricated using $1.0-\Omega \mathrm{cm}$ multicrystalline BAYSIX wafers as starting material. The ingot was cut with a special wire, thus the saw damage removal is identical for all solar cells and does not influence the result. After saw damage removal, the wafers received a phosphorous diffusion from a liquid $\mathrm{POCl} 3$ source, resulting in a lightly doped emitter with a sheet resistance of $100 \Omega / \mathrm{cm}^{2}$. Aluminum followed by silver deposition the back surface using vacuum coating machine (Edwards E306A). During the sintering, a thin layer of silicon dioxide was formed. Then the samples were loaded into the vacuum coating machine and heated for $1 \mathrm{~h}$ at $200^{\circ} \mathrm{C}$.

A thin layer of aluminum was deposited at the front surface; the thickness was measured by thickness monitor Edward's FTM5, followed by evaporation of thick layers of aluminum and silver through a mechanical mask to form the front contact grid [12-16]. In the present work we used an optimized $M I S m c-S i$ film which reduces parasitic shunting, thus the formation of the local $A l-B S F$ could be omitted. Finally the front surface was covered by a single-layer anti-reflection coating consisting of mc-Si. For comparison solar cells with a full area $A 1$ rear surface were also fabricated.

\section{THEORTICAL ASPCTS}

\subsection{Photons Absorbed by Semiconductor}

From the known experience in the solar cell experiments, when the light is shinning on a semiconductor sample, if the energy of the individual photons is greater than the semiconductor band gap, then the photons can be absorbed and/or transferring their energy to an electron. This energy leads to elevate the electron from the valence band into the conduction band, as illustrated in Fig.1. Therefore, the absorption energy creates an electron-hole pair $(E H P)$, by producing an electron in the conduction band and a hole in the valence band.

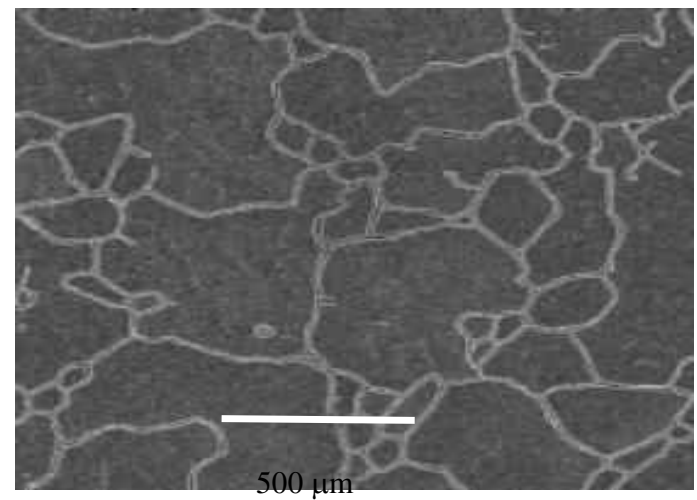

Fig. 1. Large-grains $m c-S i$ thin film 
A physical picture of EHP generation is to see the valence band electron as part of a covalent bond. When the covalent bond is broken, the electron is free to move in the crystal lattice of the semiconductor (it is now in the conduction band). The energy required to break a covalent bond is $E_{g}$, if the photon energy is less than $E_{g}$, it doesn't carry enough energy to break a covalent bond and free an electron for conduction. Since electrons cannot occupy the forbidden states between the valence and conduction bands, a photon with energy less than $E_{g}$ cannot be absorbed and will pass through the sample. In other words, an electron must either be in a covalent bond or free, not in between.

Commonly, a light with variable photon energy near the band gap energy can be used to study the bandgap of a semiconductor. Then it can observe that light with lower energy photons (long wavelength) is not absorbed while light with higher energy photons (short wavelength) is absorbed. The photon energy at which the transition between absorbing and non-absorbing behavior takes place will correspond to the band gap energy.

Because of the transition between absorption and transmission is gradual, the shape of the transition will provide some of the details of the electron inter band transitions (this is a transition between energy states in valence band and conduction band). The transition region is called the 'absorption edge'.

When $E_{p}=E_{g}$; where $E_{p}$ is a conduction band energy, a certain number of electrons might be available to make a transition from valence band to conduction band. Only those electrons exactly at $E_{v ;}$ where $E_{v}$ is valence band energy, can make the transition. As $E_{p}$ increases above $E_{g}$, more and more electrons from the valence band can possibly make the transition, so the overall probability of a photon being absorbed increases. Thus, the number of photons absorbed increases [12, 13].

\subsection{Optical Absorption, Reflection, Transmission and Scattering}

In this experiment, shining light of various wavelengths strikes a silicon samples as well as a GaAs ones. The transmitted light is then measured by a photodetector. The bandgap of the sample can be determined by observing the wavelength at which the sample begins to absorb the light. The entire light incident, reflected, transmitted or scattered by the sample, sample holder and other apparatus must be accounted in order to measure the absorption accurately. Taking into account the reflections from both front and back surfaces of the wafer, the expression for the amount of light which is transmitted through the sample may be written as [14-17]:

$$
\mathrm{I}_{\mathrm{t}}=\mathrm{I}_{0}(1-\mathrm{R})^{2} \mathrm{e}^{-\lambda \mathrm{L}}
$$

Where $L$ is the sample thickness and $\lambda$ is the wavelength. Equation (1) ignores the small amount of light that will be reflected multiple times within the sample, but this is a small effect, particularly when $\alpha$ is large. Using Eq. (1), it can determine $\alpha$ by measuring transmitted light intensity if the incident light intensity light $I_{0}$, the sample thickness $L$, and the sample index of refraction $n$, which determines $R$ are known. .

\section{3 p-n JNCTIONS I-V CHARACTERISTICS}

The current density in a forward biased $p-n$ junction is generally described by Shockley equation, 


$$
\mathrm{J}=\left\{\left[\left(\mathrm{qD}_{\mathrm{h}} / \mathrm{L}_{\mathrm{h}} \mathrm{N}_{\mathrm{d}}+\mathrm{qD}_{\mathrm{e}} / \mathrm{L}_{\mathrm{e}} \mathrm{N}_{\mathrm{a}}\right) \mathrm{n}_{\mathrm{i}}^{2}\left[\exp \left(\mathrm{q}^{\mathrm{V} / \mathrm{KT}}\right)-1\right]\right\}\right.
$$

Where $q$ is the electronic charge, $K$ is Boatzmann's constant, $V$ is the voltage across the $p$ - $n$ junction, $n_{i}$ is the intrinsic concentration, $D$ is the diffusion length and $N_{a}$ and $N_{d}$ are the acceptor and donner doping concentrations respectively. The subscripts $e$ and $h$ refer to electrons and holes, respectively, as minority carriers, that is, holes in the $n$-side and electrons in $p$-side. If $\tau$ is the charge carrier lifetime (recombination time) then $\mathrm{L}=\sqrt{ } \mathrm{D} \tau$. The Shockley expression neglects the current component that is due to recombination in the depletion region that is in the space charge layer $(S C L)$. The electron and hole concentrations across the device are depicted (in an exaggerated way). The minority carrier concentrations (e,g. hole and electron concentrations) at the space chare layer $(S C L)$ boundaries in the neutral regions ( $n$ - and $p$-regions respectively) are represented as $p_{n}(0)$ and $n_{p}(0)$. In a long diode the minority carrier concentration profile falls exponentially towards the electrode, which means that there is a concentration gradient and hence diffusion. The minority carriers therefore diffuse towards the bulk giving rise to a diode current. These arguments lead to the Shockley equation stated in Equation (2) for p-n junction long diode.

The reverse current density component due to thermal generation of electronhole pairs within the depletion region is given by:

$$
\mathrm{J}_{\mathrm{gen}}=\mathrm{qWn} \mathrm{n}_{\mathrm{i}} / \tau_{\mathrm{g}}
$$

Where $\mathrm{W}$ is the width of the depletion region and $\tau_{g}$ is the mean thermal generation time.

Thermal generation of hole-electron pairs in the depletion region occurs through generation-recombination centers and depends on carrier concentrations, crystal defects and impurities. $\tau_{g}$ in Equation (3) represents a mean thermal generation time calculated by integrating the rate of thermal generation across the depletion region. There is also a contribution to the reverse current arising from the thermal generation of minority carriers in the neutral regions within a diffusion length to the $S C L$, their diffusion to the $S C L$, and subsequent drift through the $S C L$. This is essentially the Shockley model with a negative voltage that is Equation (2) with reverse bias.

\section{RESULTS\&DISCUSION}

Figure 2 shows the effect of oxidation time intervals on the open circuit voltage. The open circuit voltage increases with the increase of the oxidation time until $60 \mathrm{~min}$ and decreases after this time or the optimum time depends on the thickness of oxidation or insulator thickness $\left(\mathrm{SiO}_{2}\right)$ [13 ]. This is consistent with the relation [14]:

$$
\mathrm{V}_{\mathrm{oc}}=\mathrm{n}\left\{\mathrm{Q}_{\mathrm{B}}+(\mathrm{KT} / \mathrm{q}) \chi^{1 / 2} \delta+(\mathrm{KT} / \mathrm{q}) \operatorname{Ln}\left(\mathrm{J}_{\mathrm{sc}} / \mathrm{A}^{*} \mathrm{~T}^{2}\right)\right\}
$$

Where $n$ is the ideality factor, $\delta$ the thickness of the interfacial layer, $Q_{B}$ the barrier height in volts, $J_{s c}$ the short circuit photogeneration current density in $\mathrm{A} / \mathrm{cm}^{2}$. $\mathrm{A}^{*}$ is the effective Richardson constant in $\mathrm{A} / \mathrm{cm}^{2} / \mathrm{K}^{2}, \chi$ the main barrier height 
presented by the interfacial layer to the flow of majority carrier, $V_{o c}$ the open circuit voltage, and $P_{\max }$ the maximum power at optimal load.

The fill factor $F F$ of the current voltage, and the load resistance decrease as shown in Figs. 3-7. The increase in the photocurrent with increasing temperature is explained by the change in the light absorption. As the temperature of the cell increases, the absorption edge shifts as a result of band gap narrowing in the crystal and number of pairs generated in the bulk increase. On the other hand, the light absorption coefficient changes with increasing temperature. As a result, the photocurrent increases with temperature [15].

The decrease in the open circuit voltage with increasing temperature is due to the change in intrinsic charge carrier density and the crystal, and $\Delta I_{s c} d \Delta T=0.00097$ $\mathrm{mAK}^{-1}$.

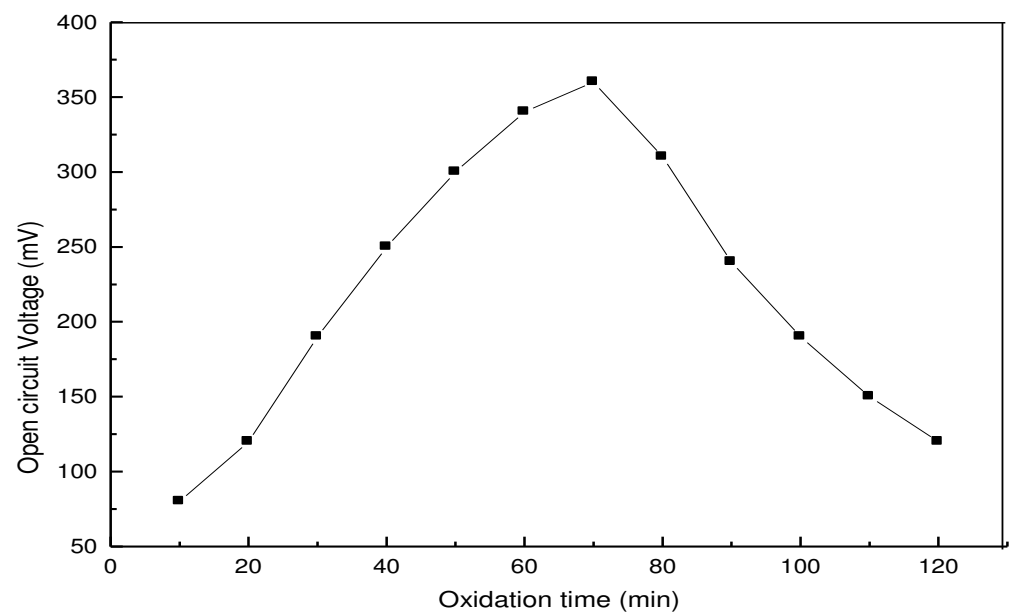

Fig. 2. Effect of oxidation time intervals on the open circuit voltage.

In our case the open circuit voltage is determined by the relation $V_{o c} \sim \operatorname{In}\left(I_{s} / I_{0}\right)$ [16], according to which $V_{o c}$ should increase with it. While a sharp increase in the dark current $I_{0}$ flowing through the $p-n$ junction decreases $V_{o c}$. The intrinsic density $n_{i}$ varies exponentially with temperature, which gives $I_{s c} I_{0} \sim n_{\mathrm{i}}$. Furthermore, narrowing of the band gap with increasing temperature increases the dark current. Consequently, the positive effect of increasing the light absorption coefficient in the long wavelength region of the spectrum is reduced to a minimum [17]. As a result, $V_{o c}$ decreases with increasing temperature according the relation $\Delta V_{o d} d \Delta T=-0.00337 \mathrm{mVK}^{-1}$. As the temperature is raised, the fill factor of the current voltage characteristic decreases, this is explained by increase in the dark current. The output power decreases when the temperature increases. This occurs mainly because of the decrease in the photovoltaic and fill factor of the current voltage characteristic. This happens in samples which have $\Delta P / \Delta T=-.00048 \mathrm{WK}^{-1}, \Delta F F / \Delta T=-0.002 \% \mathrm{~K}^{-1}$, and $\Delta R / \Delta T=-0.021 \Omega \mathrm{K}^{-1}$.

The junction current $I_{j}$ is related to the junction voltage $V$, the total current may be the sum of the ideal junction current [18], a recombination current, and a leakage current [19]. All of which can have a voltage dependence of the type shown 
under certain conditions. The short circuit current $I_{s c}$ is related to the input radiation by the following equation ${ }^{[20]}$ :

$$
\mathrm{I}_{\mathrm{sc}}=\mathrm{Q}(1-\mathrm{r})\left(1-\mathrm{e}^{\alpha \mathrm{l}}\right) \mathrm{q} \mathrm{n}_{\mathrm{ph}}\left(\mathrm{E}_{\mathrm{g}}\right)
$$

Where $Q$ is collection efficiency of $p$ - $n$ junction, $r$ is reflection coefficient of front face of solar converter, $\alpha$ is absorption coefficient in a semiconductor, $l$ is thickness of absorbing semiconductor, $n_{p h}\left(E_{g}\right)$ is the number of photons with energy greater than the band gap $E_{g}$.

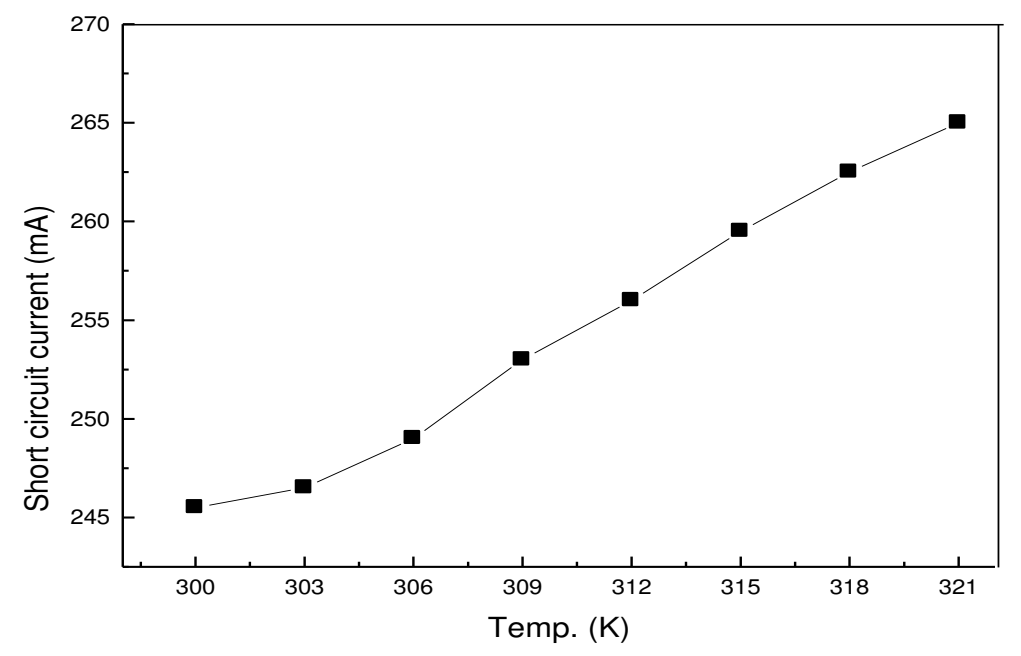

Fig. 3. Short circuit current-temperature characteristic from mc-Si solar cell.

When the $p-n$ junction is suitably located and the lifetimes are sufficiently great, $I_{s c}$ can be expressing as $[19,20,21]$ :

$$
\mathrm{I}_{\mathrm{sc}}=\mathrm{qg}\left[\mathrm{L}_{\mathrm{n}}+\mathrm{L}_{\mathrm{p}}\right]
$$

Where $g$ is generation rate of electron hole pairs per $\mathrm{cm}^{3}$ per sec., $L_{n}, L_{p}$ are the diffusion length of electrons and holes.

The temperature dependence of the short-circuit current arises primarily with the diffusion lengths, which can express as:

$$
\mathrm{L}=\left(\mathrm{D}_{\tau}\right)^{1 / 2}
$$

Where $\mathrm{D}=\left[1+\left(\mathrm{D}_{\mathrm{P}} \mathrm{D}_{\mathrm{n}}\right) 1^{1 / 2}\right]^{2}$ is the effective diffusion constant, $\tau$ is the lifetime, $D_{n}, D_{p}$ are the diffusion constant for electrons and holes.

Since the temperature dependence of the diffusion constant is $\mathrm{T}^{-1 / 2}$, the net effect on $L$ is small, it was assumed that the temperature dependence of the lifetime is determined by single-level recombination statistics of hall, which show the lifetime in the n-type region to be [21, 22]:

$$
\tau=\tau_{\mathrm{po}}\left[1+\exp \left(\mathrm{E}_{\mathrm{T}}-\mathrm{E}_{\mathrm{f}} / \mathrm{KT}\right)\right]
$$

and

$$
\tau=\tau_{\text {no }}+\tau_{\mathrm{po}}\left[1+\exp \left(\mathrm{E}_{\mathrm{T}}+\mathrm{E}_{\mathrm{f}}-2 \mathrm{E}_{\mathrm{i}} / \mathrm{KT}\right)\right]
$$


(Where $\tau_{n o}$ is the electron lifetime in material in which all traps are empty, $\tau_{p o}$ is the hole lifetime in material in which all traps are full), in the p-type region.

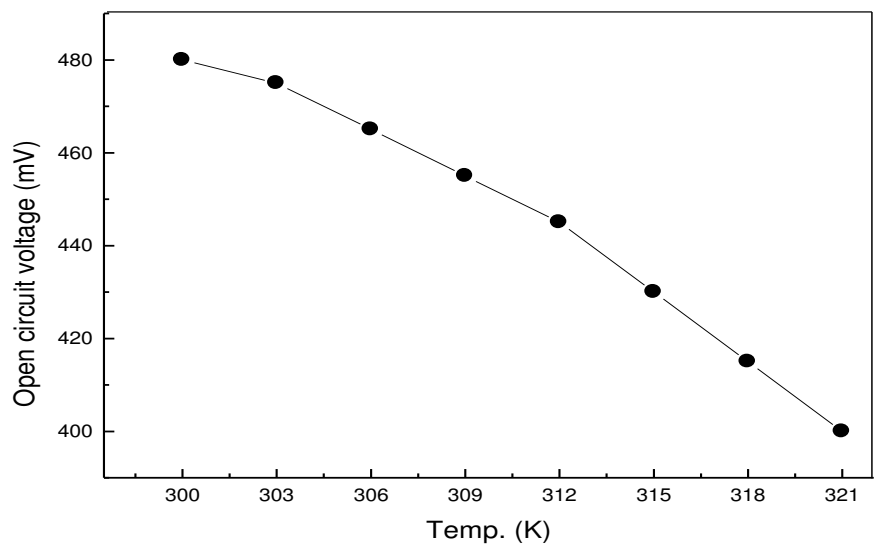

Fig. 4. Open circuit voltage- temperature characteristic for mc-Si solar cell.

The temperature dependence of the lifetime arises from the exponential terms in the foregoing equations. If the difference between $E_{f}$ and $E_{T}$ is large compared to $K T$, the exponential terms in Eq.13 and 14 are negligible, and they remain negligible as the temperature is increased until $E_{f}$ is within a few $K T$ of $E T$. Another factor in $I_{s c}$ to consider is the generation rate $g$. The generation rate increases slightly with temperature. This increase is due to the decrease in band gap, and consequently increases the number of photons, which are effective in creating electron-hole pairs.

Where $\mathrm{D}=\left[1+\left(\mathrm{D}_{\mathrm{p}} \mathrm{D}_{\mathrm{n}}\right) 1^{12}\right]^{2}$ is the effective diffusion constant, $\tau$ is the lifetime, $D_{n}, D_{p}$ are the diffusion constant for electrons and holes.

The current voltage characteristics of the devices were measured under illumination for different illumination intensities (from $300 \mathrm{Wcm}^{-2}$ into $900 \mathrm{Wcm}^{-2}$ ). The result of samples in Figs. 8 and 9, shows that the current in a device is almost directly proportional to light intensity. The current voltage characteristics of the devices were measured under illumination for different illumination intensities.

Small area $p-n$ junction silicon solar cells were fabricated. Then, the performance of these solar cells was studied under illumination using a quartz tungsten halogen lamp with an irradiance of about $(300-900) \mathrm{mW} / \mathrm{cm}^{2}$.

Figure 4 shows that the open circuit voltage increases as the dopant concentration decrease. Then, the $p$ - $n$ junction devices were studied using the constant photo current method. It found that for an illuminated sample generate photogenerated current density as follows [23, 24]:

$$
J_{\text {photo }}=\mathrm{qN}(1-\mathrm{R})\left(1-\mathrm{e}^{\alpha \mathrm{d}}\right) \eta \mu_{0} \tau \mathrm{E} / \mathrm{d}
$$

where $q$ is the electronic charge, $N$ is the flux of incident photons, $R$ is the reflection coefficient, $\alpha$ is the absorption coefficient, $d$ is the film thickness, $\eta$ is the quantum efficiency of generation of free electrons and holes, $\mu_{0}$ is the carrier mobility, $\tau$ is the carrier lifetime and $E$ is the applied electric field. In our case, there are two different layers, namely the amorphous silicon layer (emitter) and the crystalline silicon substrate (base), the above relation can be recast as follows: 


$$
\begin{aligned}
J_{\text {photo }} & =J_{\text {photo1 }}+J_{\text {photo2 }} \\
& =\mathrm{qN}(1-\mathrm{R})\left(1-\mathrm{e}^{\alpha 1 \mathrm{~d} 1}\right) \eta_{1} \mu_{01} \tau_{1} \mathrm{E}_{1} / \mathrm{d}_{1} \\
& +\mathrm{qN}(1-\mathrm{R})\left(1-\mathrm{e}^{\alpha 2 \mathrm{~d} 2}\right) \eta_{2} \mu_{02} \tau_{2} \mathrm{E}_{2} / \mathrm{d}_{2}
\end{aligned}
$$

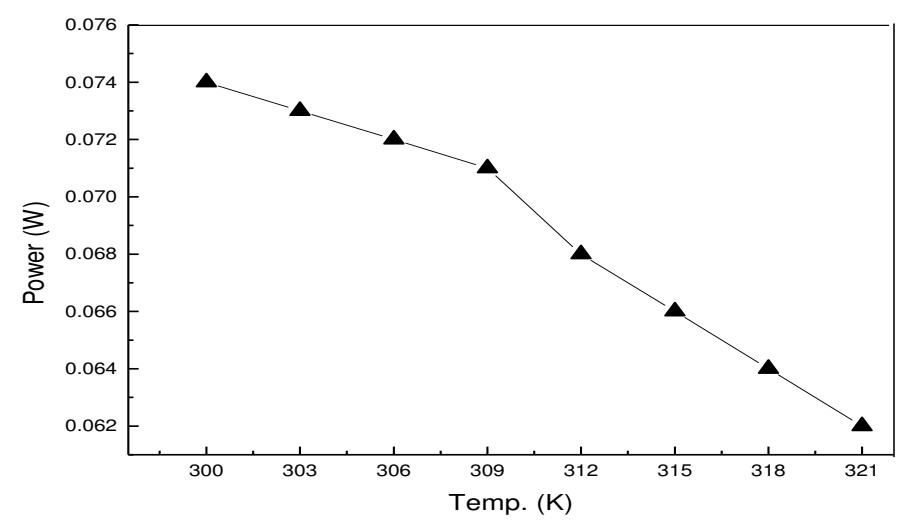

Fig. 5. Power- temperature characteristic for mc-Si solar cell.

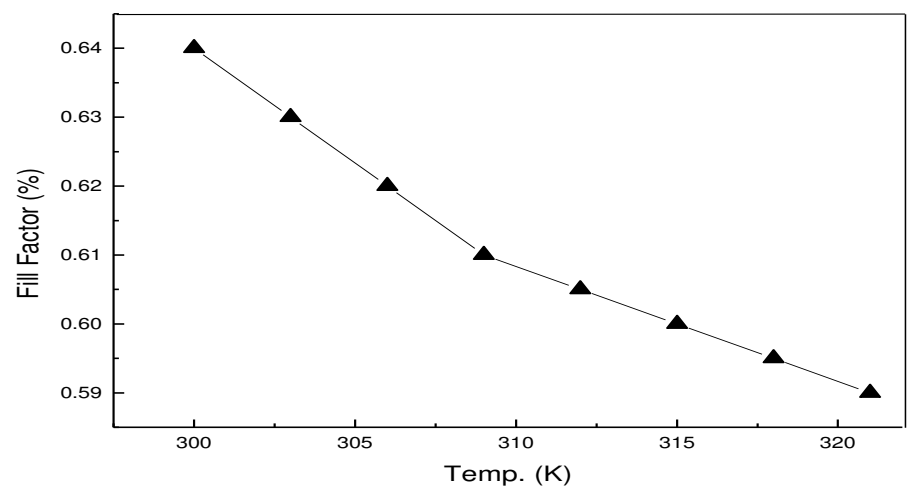

Fig. 6. Fill Factor-temperature characteristic for mc-Si solar cell.

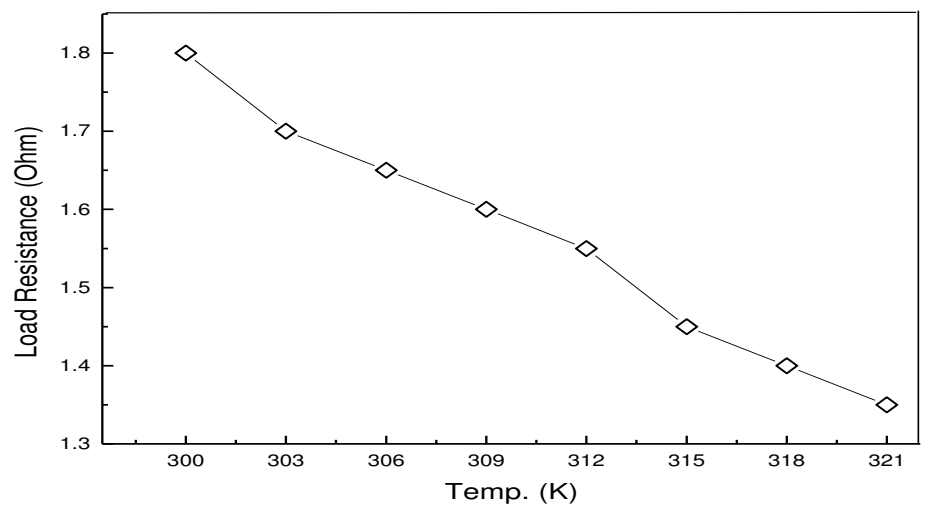

Fig. 7. Load resistance -temperature characteristic for mc-Si solar cell 
Here the terms are defined as in equation (10) except that the subscripts refer to the amorphous and crystalline silicon layers, respectively [18, 19]. Considering that, the first layer $(\mathrm{Si})$ is thin, the second layer (crystalline silicon) is thick and the examined wavelength range corresponds to energies above the silicon band gap and up to the amorphous silicon band gap, $\alpha_{1} d_{1}$ is small and $\alpha_{2} d_{2}$ is large. Hence, the above equation can be simplified to:

$$
\left.J_{\text {photo }}=\mathrm{qN}(1-\mathrm{R}) \times\left[\eta_{1} \mu_{01} \tau{ }_{1} \mathrm{E}_{1}-\eta_{2} \mu_{02} \tau{ }_{2} \mathrm{E}_{2} \mathrm{~d}_{1} / \mathrm{d}_{2}\right)+\eta_{2} \mu_{02} \tau{ }_{2} \mathrm{E}_{2} / \mathrm{d}_{2}\right]
$$

If $J_{\text {photo }}$ is kept constant as the wavelength of the incoming light is changed, then the $\mu \tau$ product is constant $[25,26]$. The electric fields and the thickness of the layers are also constant. The collection efficiency for electron hole pairs generated in the crystalline base is also considered to be constant. Thus, we obtain $[27,28]$ :

$$
1 / \mathrm{N}(\lambda)=\alpha_{1}(\lambda)\left[\eta_{1}(\lambda) \mathrm{C}_{1}-\mathrm{C}_{2}\right]+\mathrm{C}_{3}=\alpha_{\mathrm{cpm}}
$$

Where the constants $C_{i}$ are defined through equation (12). The above relationship is a measure of the optical absorption (that is, generation of electron hole pairs) and separation and collection of the generated carriers. Constants $C_{2}$ and $C_{3}$ are determined by the properties of crystalline silicon only, which is the same for all of our devices. Thus, differences in the absorption spectra indicate differences in absorption and separation of carriers in the amorphous silicon layer and the interface between the two materials.

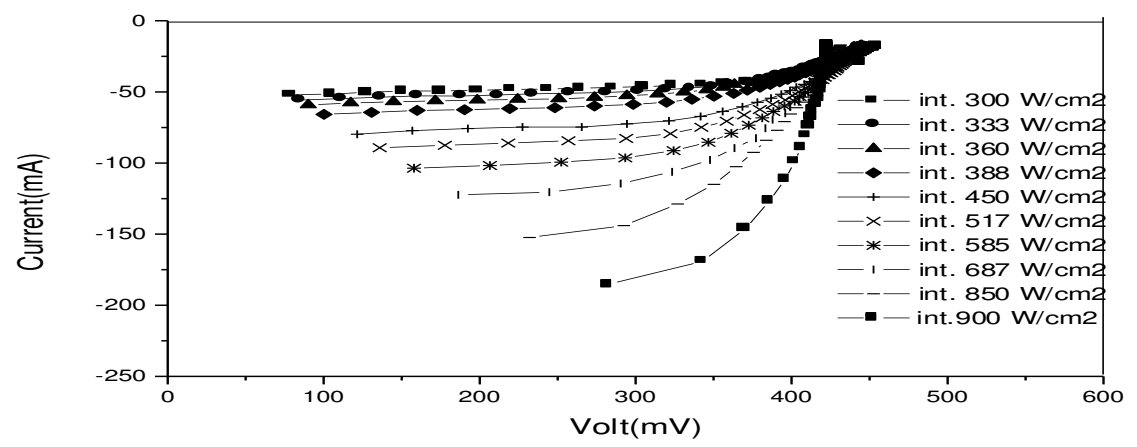

Fig. 8. IV characteristics of the p-n junction devices under illumination

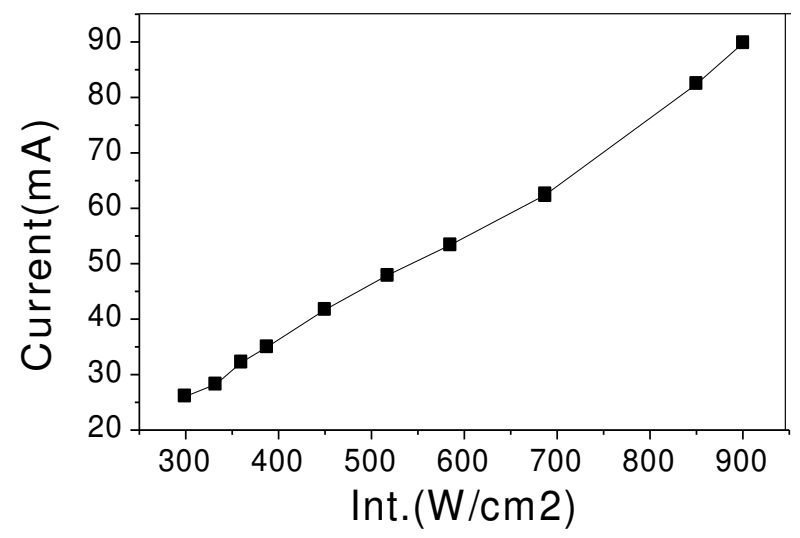

Fig. 9 Current - intensity curve 


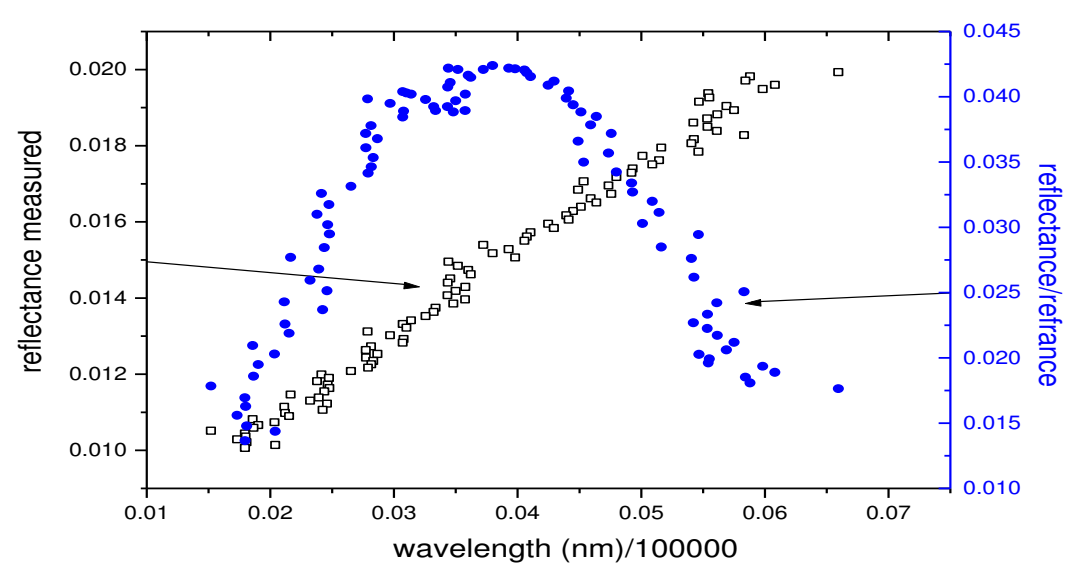

Fig.10. Surface reflectance with wavelength

It is obvious that the cell has a significantly increased long wavelength response. With inverted surface, the result of samples is shown in Figure 10. This is because the structure has more randomized surface angles. These randomized surface angles are the best for light trapping effect [29]. Light trapping is an effect, which, happens when the incident light might be bounced (trapped) between the rear and the front surface of the cell after it, has entered the cell front surface, due to total internal reflection. When the cell surface is rough, the light enters the cell substrate obliquely, and hence has more chance to be totally internally reflected at the next surface. The light trapping effect of this structure is also confirmed reflection at the weakly absorbed wavelength. This is basically the same as the best inverted structure [30].

\section{CONCLOSION}

The temperature dependence of the operating characteristics is always of great interest in the description of semiconductor devices. The most important temperature effect is through the change in open circuit voltage. It can be shown that the temperature variation of the open circuit voltage can be represented in multicrystalline silicon by the relation; $\Delta V_{o d} d \Delta T=-0.00337 \mathrm{mVK}-1$.

Since the output power of the device varies linearly with the open circuit voltage, the power decreases with temperature rise at a rate greater than 0.5 present per degree centigrade.

It can then observe that light with lower energy photons (long wavelength) is not absorbed and light with higher energy photons (short wavelength) is absorbed. The photon energy at which the transition between absorbing and non-absorbing behavior takes place will correspond to the band gap energy.

The most important loss mechanisms with respect to thin mc-Si cells are (i) optical losses, (ii) losses due to rear surface recombination and (iii) losses due to the series resistance caused by local rear contact schemes with dielectric passivity. The open circuit voltage increases as the dopant concentration decrease. The current in a device is almost directly proportional to light intensity. 
The optimum time depends on the thickness of oxidation or insulator thickness. The randomized surface angles are the best for light trapping effect. Total internal reflection is considered as the main cause of light trapping effect: After the incident light has entered the cell front surface, light may be trapped between the rear and the front surfaces of the cell.

\section{REFERENCES}

1. J.-F. Lelièvre, H. Rodriguez, E. Fourmond, S. Quoizola, J. De la Torre, A. Sibai, G. Bremond, P.-J. Ribeyron, J.-C. Loretz, D. Araujo, M. Lemiti "Evidence of intrinsic silicon nanostructure formation in $\mathrm{SiN}$ matrix deposited by various low temperature CVD techniques" physica status solid (C) (p 1401-1405),28 Mar,2007.

2. Burgelman, M, Verschraegen, J, Degrave, S, and Nollet, P, Analysis of CdTe Solar Cells in Relation to Materials Issues, "Thin Solid Films", 480-481, pp 392-398, 2005.

3. Laaziz, Y, Bennouna, A, Chahboun, N, Outzourhit, A, Ameziane, E. L, Optical Characterization of Low Optical Thickness Thin Films From Transmittance and Back Reflectance Measurements, Thin Solid Films, 372, pp. 149-155, 2000.

4. Compaan, A. D, Gupta, A, Lee, S, Wang, S, Drayton, J, High Efficiency Magnetron Sputtered Si Solar Cells, Solar Energy, 77 (6), pp. 815-822, 2004.

5. V. Sclosser, R. Ebiner, W. Markowitsh, P. Bajons, G. Klinger, A. A. El-Amin, and J. Summhammer, "Investigations of Evaporated Front Contacts along the Grain Boundaries of Multicrystalline Silicon Solar Cells" Proceedings of the 17th European Photovoltaic Solar Energy Conference and Exhibition (Munich, October 2001).

6. M. Radike, J. Summhammer, Novel process of grain boundary metallisation on mc-Si solar cell, Solar Energy Materials and Solar Cells, 65, 303-309, 2001.

7. H. Jugrez, T. Diaz, M. Pacio, G. Garcsa S., E. Rosendo, M. Rubin, G. Romero, A. Garcsa, C. Morales "Optical and electrical characterization of $\mathrm{SiO}_{2}$ films obtained by atmospheric pressure chemical vapor deposition" (p 1481-1484), 28 Mar 2007.

8. Kushev, D. B, Zheleva, N. N, Demakopoulou, Y, Siapkas, D, A New Method for the Determination of the Thickness, the Optical Constants and the Relaxation Time of Weakly Absorbing Semiconducting Thin Films, Infrared Physics, pp. 385-393, 261986.

9. J.-F. Lelièvre, H. Rodriguez, E. Fourmond, S. Quoizola, M. Lipinski, D. Araujo, G. Bremond, M. Lemiti "Electro-optical characterisation for the control of silicon nanocrystals embedded in $\mathrm{SiN}_{\mathrm{x}}$ :H films" (p 1554-1559), 28 Mar 2007.

10. B.Streetman, Solid-State Electronic Devices, Chapter $4.1,4^{\text {th }}$ Edition, PrenticeHall, EE 178 (Device Physics) textbook, 1995. .

11. Manifacier, J. C, Gasiot, J, Fillard, J. P, A Simple Method for the Determination of the Optical Constants n, $\mathrm{k}$ and the Thickness of a Weakly Absorbing Thin Film, Journal of Physics E: Scientific Instruments, pp. 1002-1004, 9, 1976. 
12. Minkov, D, Computation of the Optical Constants of a Thin Dielectric Layer on a Transmitting ubstrate from the Reflection Spectrum at Inclined Incidence of Light, Journal of the Optical Society of America A, 8 (2), pp 306, 1991.

13. L. Mittelstädt, S. Dauwe, A. Metz and R. Hezel, "Front and Rear SiliconNitride_Passivated Multicrystalline Silicon Solar Cells with an Efficiency of 18.1\%”, Prog. Photovolt. Res. Appl 10, 35-39, 2002.

14. T. Lauinger, J. Schmidt, A.G. Aberle, R. Hezel, "Record low surface recombination velocities on $1 \Omega \mathrm{cm}$ p-silicon using remote plasma silicon nitride passivity”, Appl. Phys. Lett. 68, 1232, 1996.

15. S. Dauwe, A. Metz and R. Hezel, "A Novel Mask- Free Low-Temperature Rear surface Passivity Scheme Based on PECVD Silicon Nitride For HighEfficiency Silicon Solar Cells", Proc. 16th European Photovoltaic Spec. Conference, Glasgow, U.K., 1747, 2000.

16. S. Dauwe, L. Mittelstädt, A. Metz and R. Hezel, "Experimental evidence of parasitic shunting in silicon nitride rear surface passivated solar cells", Prog. Photovolt. Res. Appl 10, 271-278 (2002).

17. Y. Zhang, A. Seger and A. Shakouri, "Optical Absorption Photoluminescence", Properties of Materials Laboratory, University of California at Santa Cruz, 2004.

18. M. Taguchi, "Prog. Photovolt": Res. Appl. 8 503, 2000.

19. T. Sawada, Conference Record, the First WCPEC, 1219, 1994.

20. Manifacier, J. C, Gasiot, J, Fillard, J. P, A Simple Method for the Determination of the Optical Constants n, $\mathrm{k}$ and the Thickness of a Weakly Absorbing Thin Film, Journal of Physics E: Scientific Instruments, pp. 1002-1004, 9, 1976.

21. Minkov, D, Computation of the Optical Constants of a Thin Dielectric Layer on a Transmitting ubstrate from the Reflection Spectrum at Inclined Incidence of Light, Journal of the Optical Society of America A, 8 (2), pp 306, 1991.

22. L. Mittelstädt, S. Dauwe, A. Metz and R. Hezel, "Front and Rear SiliconNitride_Passivated Multicrystalline Silicon Solar Cells with an Efficiency of 18.1\%”, Prog. Photovolt. Res. Appl 10, 35-39, 2002.

23. T. Lauinger, J. Schmidt, A.G. Aberle, R. Hezel, "Record low surface recombination velocities on $1 \Omega \mathrm{cm}$ p-silicon using remote plasma silicon nitride passivity”, Appl. Phys. Lett. 68, 1232, 1996.

24. S. Dauwe, A. Metz and R. Hezel, "A Novel Mask- Free Low-Temperature Rear surface Passivity Scheme Based on PECVD Silicon Nitride For HighEfficiency Silicon Solar Cells", Proc. 16th European Photovoltaic Spec. Conference, Glasgow, U.K., 1747, 2000.

25. S. Dauwe, L. Mittelstädt, A. Metz and R. Hezel, "Experimental evidence of parasitic shunting in silicon nitride rear surface passivated solar cells", Prog. Photovolt. Res. Appl 10, 271-278 (2002).

26. Y. Zhang, A. Seger and A. Shakouri, "Optical Absorption Photoluminescence", Properties of Materials Laboratory, University of California at Santa Cruz, 200420] Patrick Campbell and Martin A. Green, "Light Trapping Properties of Pyramid ally Textured Surfaces", J. Appl. Phys. Vol. 62, pp. 243-249, 1987.

27. J. Zhao, A. Wang, P. Altermatt and M. A. Green, 'Twenty-four percent efficient silicon solar cells with double layer antireflection coatings and reduced resistance loss', Appl. Phys. Lett., 66, (26), pp. 3636-8, 1995. 
28. P. Chattopadyay, Solid -state Electronics 4, 587, 1993.

29. Acharya Prayfulla, Solid State Electronics, 25 (12), 1255, 1982.

30. D. Yeghikyan, N. P. Kherani, T. Kosteski, B. Bahardoust, I. Milostnaya, T. Allen, S. Zukotynski 19th European Photovoltaic Solar Energy Conference 1621, 2004.

\section{دراسـة لخلية شمسية سليكونية رقيقة عديدة التبلور}

اعتمدت الدراسة على تصنيع الخلية الرقيقة من السبلكون عديد التبلور وذلك للاهتمام بتقليل التكلفة حيث ان استخدام هذا النوع من الخلايا غير مكلف. ودراسة مثل هذا النوع من الخلايا يعتمد على كيفية الحصول على اعلى اعلى كفاءة من خلال دراسة تأثنير بعض المؤثرات الفيزيائية التى تلعب دورا هاما فى كفاءة وخرج الخلية. و هذه العوامل يتم التحكم فهها

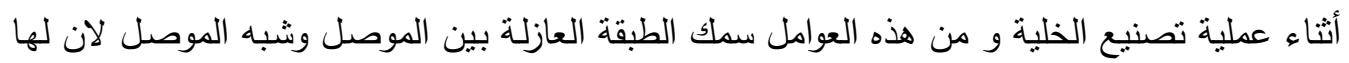
دور هام فى قيمة كلا من قيمة التيار والفولت واستطعنا الحصول على افضل سمك بعطى افضل نتيجة و ذللك بالحصول على معدل الزمن المناسب لتصنيع العينة والذليؤدى الى اعلى قيمة للسمك ولى وافضل فئل

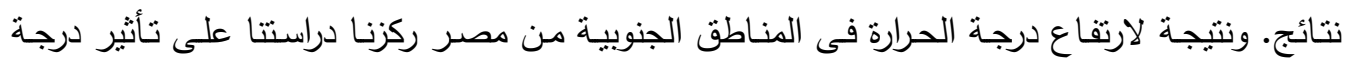

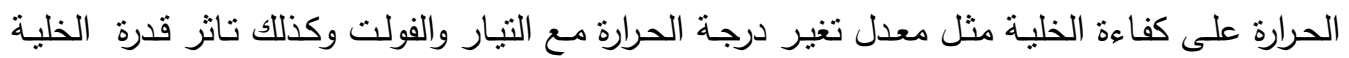
بارتفاع درجـة الحرارة. ووجد ان ارتفـاع درجـة الحرارة بدرجـة كبيـرة يقلـل مـن الكفاءة النهائيـة للخليـة الثمسية. 